\title{
Proposição para o Gerenciamento de Resíduos da Construção e Demolição de Cuiabá
}

Proposition for waste management of construction and demolition of Cuiabá

\author{
Roberto Naime'; Eduardo Figueiredo Abreu²; Dioni Maria Attilio ${ }^{3}$ \\ 'Programa de pós graduação em Qualidade Ambiental - UNIVERSIDADE FEEVALE - Novo Hamburgo, RS, Brasil, \\ ${ }^{2}$ Esp., Engenheiro florestal da SEMA-MT - Centro Político Administrativo,Cuiabá, MT, Brasil \\ 3 Engenheira Sanitarista Cuiabá, MT, Brasil,
}

\section{Resumo}

A questão da gestão de resíduos sólidos em todas as suas dimensões tem sido negligenciada no Brasil e as consequências sociais, econômicas e ambientais tem sofrido várias consequências devido a esta incúria que se propaga desde o setor público e atinge os empreendedores e a própria sociedade. Se faz necessária a criação de uma nova consciência sobre o problema, com a adoção de uma postura pró-ativa que não apenas reaja às catástrofes, mês trabalhe de forma permanente e sistêmica para realizar adequada gestão ambiental da questão, minimizando impactos que afetam diretamente a qualidade de vida das populações. Só é possível praticar gestão da realidade que se conhece. Por isto este trabalho realiza um levantamento para subsidiar a questão dos resíduos sólidos de construção e demolição na cidade de Cuiabá e discute o gerenciamento destes resíduos dentro do contexto da lei municipal que visa disciplinar a questão, discutindo medidas que podem auxiliar na otimização da gestão destes resíduos sólidos e da melhoria da qualidade de vida das populações.

Palavras Chave: resíduos, construção, demolição

\begin{abstract}
The issue of solid waste management in all its dimensions has been neglected in Brazil and the social, economic and environmental consequences have been a number due this neglect that propagates from the public sector and reaches the entrepreneurs and the society itself. It is necessary to create a new awareness of the problem, by adopting a proactive stance that not only respond to disasters, months of work permanently and systems to perform that directly affect quality of life of populations. You can only practice management actually know. Therefore, this study conducts a survey to support the issue of solid waste from construction and demolition in the city of Cuiabá. And discusses the managementof these wastes within the context of municipal law which regulates the issue, discussing measures that can help optimize the management of solid waste and improving the quality of living.
\end{abstract}

Keywords: waste, construction, demolition 
Não é possivel separar o econômico do ambiental, como não é possível separar o social do político e do cultural.

Washington Novaes

\section{INTRODUÇÃO}

A questão dos resíduos gerados em ambientes urbanos atinge contornos muito graves, pela ínfima presença de soluções adequadas quer para os efluentes líquidos ou resíduos sólidos. Este não deixa de ser um quadro típico dos países em desenvolvimento, mas nem por isso deve permitir qualquer postura condescendente, passiva e negligente da sociedade, como hoje se observa generalizadamente.

Os dados levantados no Censo de 1991 apontam que menos de $64 \%$ dos domicílios brasileiros possuem algum sistema de destinação do esgoto sanitário, sendo que, do esgoto coletado nos $49 \%$ dos domicílios que são atendidos pela rede pública de coleta, $80 \%$ não recebem qualquer tipo de tratamento, sendo despejado diretamente no solo ou nos corpos d'água, gerando sérios impactos aos ambientes de vida. O mesmo Censo aponta que quase $79 \%$ dos domicílios têm seus resíduos domiciliares coletados, mas que $76 \%$ desse material são depositados a céu aberto, sem qualquer tipo de tratamento ou controle (CALDERONI, 1999).

A gravidade dessa situação é indicada pela estimativa do Ministério da Saúde de que as carências dos serviços e ações de saneamento sejam responsáveis, no Brasil, por $65 \%$ das internações hospitalares Por exemplo, só a diarréia é responsável pela morte de 50.000 crianças ao ano (CALDERONI, 1999). É a "epidemia surda" da carência de saneamento, que pune, num país sem lutas nem guerras, principalmente as populações de baixa renda, marginalizadas no processo econômico.

O Censo Geral do próximo ano deverá revelar um novo quadro, mas, para o País como um todo, não deverão acontecer alterações significativas, em função das dificuldades econômicas vividas pelos municípios e da crescente omissão do governo federal na última década.

Os resíduos gerados nas atividades construtivas têm parte da responsabilidade no quadro acima descrito. São gerados em expressivos volumes, não recebem solução adequada, impactam o ambiente urbano e constituem local propício à proliferação de vetores de doenças, aspectos que irão agudizar os problemas de saneamento nas áreas urbanas.
Os resíduos de construção e demolição são parte dos resíduos sólidos urbanos que incluem também os resíduos domiciliares com todos os problemas anteriormente relatados. Porém, para os resíduos de construção e demolição há agravantes: o profundo desconhecimento dos volumes gerados, dos impactos que eles causam, dos custos sociais envolvidos e, inclusive, das possibilidades de seu reaproveitamento fazem com que os gestores dos resíduos se apercebam da gravidade da situação unicamente nos momentos em que, acuados, vêem a ineficácia de suas ações corretivas.

Este estudo parte da análise dos dados obtidos na Área de Transporte e Transbordo (ATT) de Cuiabá, buscando avaliar a situação atual da gestão desse tipo de resíduo na capital mato-grossense, demonstrando

(a) a precariedade de informações sobre os resíduos de construção e demolição nos documentos técnicos que sustentam a formulação de planos de gestão de resíduos sólidos;

(b) a efetiva geração de resíduos de construção e demolição;

(c) os impactos da significativa massa de resíduos no ambiente urbano e nas economias locais, em decorrência da ineficácia do modelo de gestão atualmente adotado; (d) o potencial da proposta de implantação de uma gestão diferenciada dos resíduos de construção e demolição como solução adequada e sustentável;

(e) os resultados obtidos apontam para a necessidade da adoção de novas práticas de gestão que incluem à semelhança do que já ocorre em países desenvolvidos do Hemisfério Norte, a reciclagem dos resíduos como condição de sustentação das ações propostas.

Esse estudo pretende abordar a situação do gerenciamento dos resíduos de construção civil na capital do Estado de Mato Grosso, tendo como referencial de pesquisa a Área de Transporte e Transbordo (ATT), avaliando tecnicamente o modelo vigente de gestão, bem como, propondo adequações e melhorias para o setor.

\section{TRABALHOS ANTERIORES}

A escalada civilizatória da humanidade caracterizou-se inicialmente pelo desenvolvimento da agricultura, como fonte segura de alimentos, e 


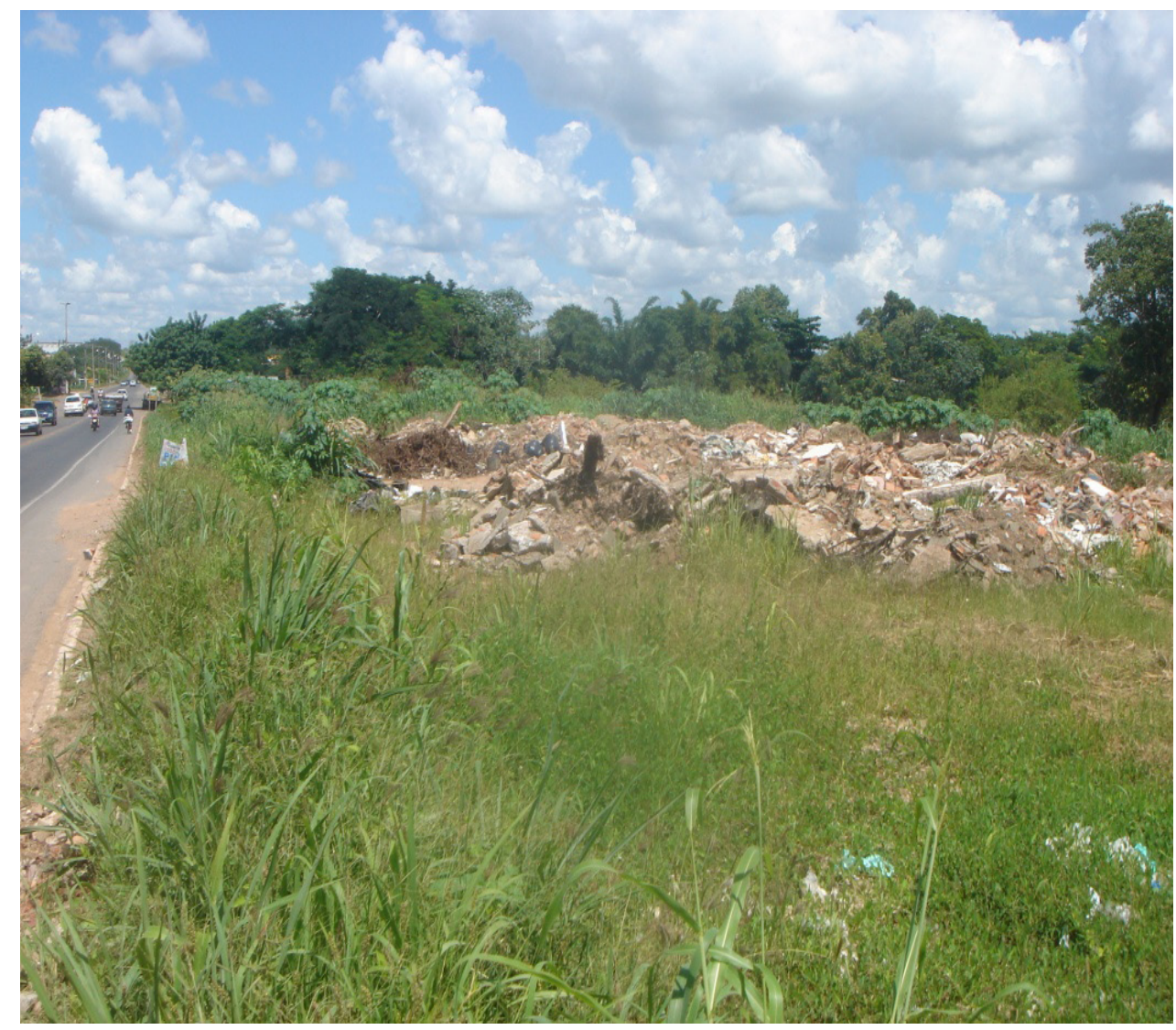

Figura 1: Vista de descarte irregular de RCD na margem Avenida Mario Andreazza, em

Várzea Grande, MT

prosseguiu com a urbanização, a vida em vilas e cidades, como imperativo de bem estar.

Estes processos, reunindo em um mesmo lugar populações sempre crescentes, ocasionaram como conseqüência direta grande geração de resíduos. Estes resíduos acumulados tornam-se fonte de desconforto e doenças, conforme figura 1, exigindo providências das lideranças e governantes.

Um dos primeiros exemplos de providências sanitárias sobre os resíduos urbanos são as leis adotadas em Ur, na Mesopotâmia, por volta de 2000 a.C., que segundo informam ABRAMS e WRINGLEY (1978), destinam um sítio, fora das muralhas, como local de depósito dos dejetos urbanos, obrigando os moradores a fazerem este transporte.

Segundo CLARK (1991), Roma, no final do Séc. I, a.C., contava com mais de um milhão de habitantes e seus principais problemas urbanos eram o transito de carroças, o abastecimento de água precário e os dejetos humanos, cobrindo a cidade de ruído e fedor insuportável. A prática de lançar o lixo pelas janelas era corrente e mereceu inclusive éditos de Augusto, prevendo multas e prisão contra tais atos.

O mesmo Imperador delimitou um lugar, ás margens do Tibre, para o depósito do lixo da cidade. Atitudes semelhantes, de delimitação de sítios de despejo, proliferaram por todo o mundo nos séculos seguintes, dando-se conta dos resíduos acumulados em simples processos de disposição em locais determinados, preferentemente fora da área urbana.

Segundo RUTHERFURD (2000), em Londres, no ano de 1822 foi feita a primeira concessão para transporte de lixo urbano, da cidade para áreas definidas no campo, sendo permitido ao coletor apropriar-se dos bens que nele se encontrasse. $\mathrm{O}$ mesmo autor registra que, já no ano de 1819 , era corrente a profissão de "coletores do rio", onde indivíduos faziam a recuperação de objetos levados pela corrente do Tamisa, local preferencial de despejo do lixo urbano.

Esta prática, simples acúmulo em locais definidos, dava conta das necessidades urbanas e era comum até iniciar-se a chamada Revolução Industrial, no Século XVIII. Neste momento o volume de produção, bem como as alternativas de combinação de elementos decorrentes do desenvolvimento da físico-química, alterou para sempre o padrão de emissão de resíduos e a capacidade do solo de absorvê-los. 
Conforme expõe BISIO e XANTHOS (1995), a descoberta dos catalizadores no início dos anos 1950 proporcionou uma proliferação de materiais plásticos versáteis, tornando-os os elementos principais do desenvolvimento da indústria química atual. Por terem baixo custo de produção e serem quimicamente inertes, são utilizados prioritariamente em embalagens e como componentes de diferentes objetos de consumo.

Segundo MANO, PACHECO e BONELLI (2005), a produção mundial de polímeros, em 2004, ultrapassava 200 milhões de toneladas de material bruto que, após processadas nas indústrias de bens de consumo final e utilizadas pela sociedade, acabam descartados no ambiente.

Esta capacidade crescente de geração de novos produtos, combinada com o crescimento populacional e a urbanização, acaba por provocar, nas palavras de AB'SABER (1999, p. 249), uma "verdadeira avalanche de geração de resíduos, que é, juntamente com o abastecimento de água, o mais sério problema de gerenciamento urbano dos tempos modernos".

O mesmo autor chama a atenção para a urgência de estudos sobre o que denominou "metabolismo urbano", afirmando que as cidades assemelham-se a um organismo vivo, onde circulam fluxos complexos de materiais e energia, todos relacionados a processos culturais e econômicos, onde a cada entrada corresponde uma descarga de resíduos sólidos, líquidos ou gasosos.

Este processo de metabolismo urbano referencia-se ao conceito de autopoiese que tem sido muito desenvolvido por autores como EIGENHEER (2003) e GRIFFITH e BERDAGUE (2006). Em última análise o ecossistema urbano é um importador de matéria (alimentos e artefatos) e exportador de resíduos (lixo para os resíduos sólidos e esgotos para os efluentes líquidos.

As condições de cada centro urbano são profundamente afetadas e definidas por diversas condições, entre elas a geologia e a fisionomia da paisagem, a hidrologia e os conceitos culturais que presidiram a ocupação do terreno, acrescenta que, tanto quanto estas, as condições de estrutura, tamanho e funcionalidade do organismo urbano, são responsáveis por seu metabolismo.

Cada centro urbano é um caso diferente de outro e por conta destas condições os estudos comparados podem e devem ser estimulados, pois problemas específicos de um podem contribuir para a solução de dificuldades semelhantes em outro centro.

AB'SABER, 1999, pág. 250, finaliza, afirmando que "estudos de metabolismo urbano, por tudo isso, interessam profundamente ás prefeituras municipais". A mesma preocupação é revelada por MACHADO e MORAES (2004) ao afirmarem que estudos desta natureza, que revelem as condições de geração de resíduos sólidos, líquidos ou gasosos e suas alternativas de tratamento ou disposição são importantes tanto para a comunidade científica como para as administrações municipais.

Lembram ainda os autores que tendo a ciência demonstrado à estreita relação entre o meio ambiente e a qualidade de vida, cabe aos administradores públicos utilizarem estas descobertas e tecnologias para melhor desempenharem suas tarefas.

Estudos desta natureza, na área do gerenciamento urbano, especialmente no que concerne aos resíduos sólidos, têm encontrado inestimável auxílio na Teoria Geral dos Sistemas. Esta Teoria, proposta por BERTALANFFY (1975), possui conceitos que obrigam a compreensão integrada de diversas ciências e técnicas administrativas e operacionais, na concepção do processo de gestão dos Sistemas de Resíduos Sólidos.

A teoria afirma que os sistemas devem ser analisados universalmente, evidenciando as interdependências de suas partes. $\mathrm{O}$ aproveitamento econômico dos resíduos se insere num sistema, qual sejam o sistema de coleta, triagem, classificação e comercialização para reciclagem. Em igual sentido GRIFFITH e BERDAGUE (2006) contribuem ao afirmaram que é necessário alterar a visão tradicional dos profissionais de diversas áreas científicas, acostumados a enxergarem a degradação ambiental como um leque de vertentes dispersa.

A tendência de cada especialista é de trabalhar em um campo técnico restrito, o que tem dificultado o entendimento tanto das causas da poluição como de suas possíveis soluções, e GRIFFITH e BERDAGUE (2006), discutindo o conceito de autopoiese das megalópoles e dos sítios urbanos em geral, advogam a tese de que a causa primária da degradação ambiental é a cidade, ou o meio urbano, num sentido amplo. GRIFFITH e BERDAGUE (2006) procuram enxergar o todo, e o "holos" de seu sistema é a cidade e por isto a degradação ambiental passa a ser conseqüência do meio urbano. Estes autores insistem ainda que todo o tipo de degradação ambiental é gerado para atender as necessidades urbanas, concluindo pela urgência em estudos integrados que permitam á cidade viver com menor consumo de recursos e menor geração de resíduos.

Analisando este problema dos resíduos sólidos, NAIME e GARCIA (2004) registram que 
no decorrer dos tempos a solução tradicional das mais diversas comunidades urbanas foi o acúmulo dos resíduos, após coletados de diversas formas, em terrenos especialmente destinados a tal depósito.

A regra geral sempre foi à absoluta ausência de estudos técnicos para esta escolha, seguida, evidentemente, por completa falta de monitoramento das possíveis conseqüências. Estes locais receberam a denominação de "lixões", por retratarem a mistura absoluta dos diversos resíduos gerados pela sociedade.

O chorume, líquido decorrente da decomposição das substâncias lançadas ao lixo, afeta às reservas de água, tanto superficiais e subterrâneas, bem como os solos adjacentes. Neste sentido, NAIME (2005) afirma que o principal risco ambiental decorrente da decomposição dos resíduos é sua capacidade de lixiviação, ou seja, a operação de separação de substâncias por meio de lavagem, com sais dissolvidos em água.

ALMEIDA (2005) alerta que este processo de lixiviação dos resíduos sólidos é ao lado do lançamento de esgotos "in natura", a principal causa da proliferação na água de substâncias capazes de interferir com o sistema hormonal de homens e animais. Desta forma o lançamento irresponsável de resíduos no meio físico promove sua contaminação, ás vezes de forma irreversível.

Incisivo, MONTEIRO (2001) denominou a prática de disporem-se os resíduos sólidos em lixões ou vazadouros, de procedimentos primitivos e irresponsáveis, pelos perigos fáticos e potenciais ao ambiente e á saúde humana, reivindicando dos poderes públicos uma tomada de posição, afirmando que o conhecimento científico e tecnológico atual oferece alternativas adequadas a esta questão. Ainda assim, os dados da ultima Pesquisa Nacional de Saneamento Básico (IBGE, 2000), indicam que, em 1999, 20,82\% dos resíduos sólidos coletados no Brasil, equivalentes a 34.399 t/dia, são assim dispostos.

O conhecimento dos danos causados ao meio ambiente por tais procedimentos exigiu o desenvolvimento de diversos processos de resolução desta problemática dos resíduos sólidos, tanto na área de gestão dos sistemas como na área de engenharia de disposição e tratamento dos mesmos.

Os conceitos de gestão passam a defender a coleta sistemática dos resíduos gerados nas áreas urbanas e estimulam alternativas no campo da engenharia sanitária para a coleta, tratamento e disposição de resíduos. Estes processos de engenharia são cada um a seu tempo e sob determinadas condições, eficientes no controle dos danos reais e potenciais da geração de resíduos.
O primeiro modelo de disposição de resíduos a ser desenvolvido sob esta ótica foi o aterro controlado, uma evolução do primeiro tipo de depósito, e caracteriza-se por adotar um envolvimento tecnológico singelo em seu planejamento e operação. A principal medida de sua concepção é a localização afastada da área urbana e o recobrimento periódico dos resíduos com uma camada de solo, evitando o desenvolvimento da fauna sinantrópica associada, tais como moscas, mosquitos, baratas, ratos, urubus (NAIME, 2005).

A evolução deste modelo foi o aterro sanitário, uma obra de engenharia complexa e dependente de planejamento, execução e operação criteriosos. Na descrição de MANO, PACHECO e BONELLI (2005), um aterro sanitário consiste em um local de processamento dos resíduos sólidos onde se promove o confinamento destes em camadas ou células devidamente compactadas e revestidas com material inerte e de baixa permeabilidade, neles gerando reações físico-químicas diversas, que fazem a decomposição dos resíduos, gerando calor, gás, e chorume.

O chorume é a água combinada com gorduras, ácidos e diversos componentes lixiviados, formando um composto extremamente poluente, que necessita de tratamento específico em instalações apropriadas.

Por sua vez, HYND, GRACE e DODD (2004), ao estudar os aspectos físicos e químicos do chorume e o comportamento geológico de diversos aterros sanitários, defendem a adaptação destas instalações para a captura e utilização do gás metano. Os autores são incisivos ao afirmarem que a eventual falta de benefício econômico desta adaptação será compensada pelos benefícios ambientais á camada de ozônio e de segurança física aos trabalhadores.

Outra forma de destino final é o co-processamento. È um método caro e circunscrito á eliminação de resíduos perigosos, especialmente pela segurança do processo, sendo definido por NAIME (2005, p. 59), como "a destinação final dos resíduos para queima, junto com outros materiais combustíveis ou alimentadores de fornos de cimento". Já a compostagem, muito utilizada no meio rural para decomposição e aproveitamento de esterco animal e restos culturais, é uma alternativa para a porção orgânica dos resíduos urbanos.

Segundo GUIMARÃES (2000), é uma prática que deve levar em consideração a disponibilidade de terreno apropriado, técnicas de arejamento e revolvimento da massa orgânica e as condições gerais de clima, incluindo insolação e o regime de chuvas. O composto gerado tem 
utilização prioritária na recomposição de terrenos degradados e pode contribuir para a melhoria de diversos cultivares.

A outra alternativa de tratamento dos resíduos sólidos é a recuperação de energia mediante a utilização dos rejeitos na alimentação de fornos geradores de vapor e energia elétrica. É um método dispendioso que somente se viabiliza quando comparado aos custos de aquisição de outras formas de energia, sempre combinadas com a pouca disponibilidade de locais para depósito dos resíduos, item fundamental para viabilizar os vultuosos investimentos dispendidos nestes sistemas.

Outro fator a aumentar o custo destas instalações é a necessidade de utilização de filtros adequados, que evitem o lançamento de dioxinas e furanos na atmosfera. Estas substâncias, derivadas da queima de matérias oriundas da transformação de hidrocarbonetos, têm características cancerígenas.

Estas combinações de exigências explicam o fato de que instalações deste tipo são encontradas apenas na Europa e Japão, onde a combinação de necessidade de geração de energia, pouca disponibilidade de áreas para aterros e o desenvolvimento tecnológico na área de filtros atmosféricos permitem seu uso (NAIME, 2005).

\section{MATERIAIS E MÉTODOS}

A pesquisa executada neste trabalho é de natureza básica ou fundamental, almejando, no dizer de JUNG (2004, p. 149), [...] a aquisição sistemática de conhecimentos sobre a natureza social, biológica ou tecnológica, com o propósito de melhoria da qualidade de vida.

O propósito final é a oferta de alternativas de concepção, desenho e práticas gerenciais, que possam aliar, neste particular sistema de gestão de resíduos sólidos, economicidade e melhoria da qualidade ambiental.

Em relação aos objetivos, a pesquisa caracteriza-se como descritivo-exploratória. De acordo com JUNG (2004, pág. 152):

O processo descritivo visa à identificação, registro e análise das características, fatores ou variáveis que se relacionam com o fenômeno ou processo. [...] A pesquisa exploratória visa à descoberta, o achado, a elucidação de fenômenos ou a explicação daqueles que não eram aceitos apesar de evidentes.
Quanto ao procedimento, é empregado o Estudo de Caso, definido por GIL (2002), como uma pesquisa descritiva que tem por objetivo principal a descrição das características de determinada população ou fenômeno, além das relações entre as variáveis que estes estabelecem entre si. Uma das peculiaridades mais significativas de estudos que podem ser assim classificados é a utilização de técnicas padronizadas de coleta de informações, tais como o questionário e a observação sistemática.

Semelhantemente, JUNG (2004) afirma que o estudo de caso pode ser definido como um procedimento de pesquisa que investiga um fenômeno dentro de um contexto local, real e é especialmente apropriado quando os limites entre o fenômeno e seu contexto não estão claramente definidos.

Por outro lado ainda contamos com a posição de Vergara (2004), que refere ser o estudo de caso aquele circunscrito a uma ou poucas unidades de estudo, sendo estas pessoas, famílias, empresas, órgão público, comunidade ou até um país. Qualquer um destes conjuntos de elementos da pesquisa pode constituir-se em um verdadeiro universo de exploração do conhecimento.

Portanto, a metodologia adotada neste trabalho é do tipo teórico-prática, vinculando os principais conceitos sobre o gerenciamento de resíduos sólidos de construção e demolição com a observação do sistema na cidade de Cuiabá - MT, em um estudo de caso.

A metodologia específica foi gravimétrica a partir dos dados acompanhados, coletados e obtidos na área de transbordo e transporte de resíduos sólidos de construção e demolição na cidade de Cuiabá, capital do estado do Mato Grosso.

\section{PROPOSIÇÕES DE GERENCIAMENTO DOS RESÍDỦOS DE CONSTRUÇÃO E DE- MOLIÇÃO DE CUIABÁ}

O Núcleo Permanente de Gestão do PGRCD de Cuiabá, no desenvolvimento de suas atribuições gerenciais definidas pelo art. 48 do Decreto 4761/2009 apresentou o primeiro relatório gerencial, referente ao período de abril a Novembro/2010.

No Quadro 1, as Informações descritas foram coletadas do Diagnóstico Geral sobre Resíduos Sólidos da Construção Civil elaborado em Outubro/2006 pela consultoria Informações e Técnicas (I\&T).

Consideradas taxas anuais (t/hab.ano), para Cuiabá foi encontrada a taxa de 0,46 , tendo sido encontrados para alguns municípios a variação 
Quadro 1: Estimativa final da quantidade de RCD gerado em Cuiabá (Abril,2006)

\begin{tabular}{|l|c|}
\hline \multicolumn{1}{|c|}{ ESTIMATIVA } & TONELADAS DIÁRIAS \\
\hline Provável geração de RCD em novas edificações (Qedif.) & 217 \\
\hline $\begin{array}{l}\text { Massa de RCD coletada em reformas e ampliações } \\
\text { (Qref.) }\end{array}$ & 367 \\
\hline Massa de RCD coletada pelo poder público & 201 \\
\hline Provável geração total de RCD & 785 \\
\hline
\end{tabular}

Fonte: Seminfe, I\&T (PMC,2006)

de 0,38 a 0,68 t/hab.ano. No Quadro 2 a seguir, geração de resíduos sólidos no município de Cuiabá, por tipologia.

A construção civil é uma das indústrias que mais utiliza recursos naturais e é, também, a maior geradora de resíduos, sendo que a tecnologia construtiva adotada no Brasil favorece o desperdício de materiais. Um grande problema relacionado à construção civil é a geração de resíduos.

Os resíduos de construção e demolição (RCD) ocupam grande volume para disposição final. Considerando que $13 \%$ das cidades brasileiras pesquisadas no censo de saneamento possuem aterros sanitários, $7 \%$ possuem aterros especiais e que, apenas, $5 \%$ possuem usinas de reciclagem, deve-se propor e implementar métodos de tratamento de resíduos (IBGE, 2000).

A destinação dos RCD não é o único problema ambiental da construção civil, a exploração de matérias-primas também causa grandes impactos ambientais. Estimativas para 2006 previram o consumo de 212 x $106 \mathrm{t}$ de areia de $146 \times 106 \mathrm{t}$ de pedra britada, totalizando o consumo destes agregados em 1,9 t/hab./ano (DNPM, 2007), utilizados para a produção do concreto, de argamassas, de lastros, entre outros. Estes agregados naturais representam recursos não-renováveis e sua exploração causa impactos ambientais.

A obtenção da areia, um dos agregados muito utilizados na construção civil, se dá pela exploração de leitos de rios, o que causa impactos ambientais, e, como conseqüência, a degradação do curso d'água devido a retirada da camada vegetal.
Os órgãos ambientais têm restringido esta atividade, entretanto, a areia ainda possui um custo de aquisição muito competitivo, pois o extrator não paga pela matéria prima, somente pela atividade de extração e transporte. Portanto, devido ao baixo custo torna-se difícil a substituição deste material por outro de menor ou igual valor agregado. A exploração da pedra britada, outro agregado importante, é realizada pelo desmonte da rocha com explosivos e posterior britagem.

Visando a diminuição dos impactos ambientais da exploração de minerais para a construção civil, existem estudos para a substituição tanto da areia quanto da pedra britada por materiais alternativos que não causem impactos ambientais.

Atualmente, os RCDs são reutilizados com função não estrutural, por isso deve-se caracterizar as frações deste resíduo e reutilizá-los substituindo, parcialmente ou totalmente, a areia e a brita. Assim, podem tornar-se agregados substitutos de baixo custo, sendo então competitivos economicamente e gerando um grande benefício ambiental que é a sua não-disposição.

Como especificado pela Resolução CONAMA n ${ }^{\circ}$ 307/02 (CONAMA, 2002), que estabelece diretrizes, critérios e procedimentos para a gestão dos resíduos da construção civil (RCC), os quais devem ser seguidos pelos geradores de resíduos, a disposição dos RCDs não pode ser feita em aterros sanitários, somente em aterros especiais. Considerando que apenas $17,32 \%$ dos municípios brasileiros têm aterros sanitários e $9,66 \%$ possuem aterros de resíduos especiais (IBGE, 2000) pode-se

Quadro 2: Estimativa gravimétrica da geração de resíduos sólidos de Cuiabá por dia e por tipologia.

\begin{tabular}{|c|c|c|c|c|}
\hline $\begin{array}{c}\text { VOL - Resíduos } \\
\text { Volumosos (t/dia) }\end{array}$ & $\begin{array}{c}\text { DOM - Resíduos } \\
\text { Domiciliares } \\
(\mathrm{t} / \mathrm{dia})\end{array}$ & $\begin{array}{c}\text { RSS - Resíduos de } \\
\text { Serviços de Saúde } \\
(\mathrm{t} / \mathrm{dia})\end{array}$ & $\begin{array}{c}\text { RCD - Resíduos da } \\
\text { Construção e Demolição } \\
(\mathrm{t} / \mathrm{dia})_{-}\end{array}$ & $\begin{array}{c}\text { TOTAL } \\
(\mathrm{t} / \mathrm{dia})_{-}\end{array}$ \\
\hline 41,4 & 374,4 & 7,3 & 785,4 & $1.208,5$ \\
\hline $3 \%$ & $31 \%$ & $1 \%$ & $65 \%$ & $100 \%$ \\
\hline
\end{tabular}

Fonte: Seminfe, I\&T (PMC,2006) 
inferir que grande parte dos RCD é disposta indevidamente. Como conseqüência dessa resolução alguns municípios criaram decretos que regulamentam Planos de Gerenciamento de Resíduos da Construção Civil, isto porque esta resolução estabelece que a responsabilidade dos municípios a criação, implantação e acompanhamento das diretrizes especificadas nos decretos municipais. Tais decretos tornam obrigatório aos geradores a gestão, incluindo reciclagem, reaproveitamento e destinação de resíduos.

Em Cuiabá, a Lei Municipal nº494/2007 instituiu o Sistema de Gestão Sustentável de Resíduos de Construção Civil e Resíduos Volumosos, e que contempla também a implantação de 24 ecopontos que servirão para destinação de entulhos de até $1 \mathrm{~m}^{3}$ sem ônus para o pequeno gerador. Essa Lei veio atender a Resolução CONAMA n³07, de $05 / 07 / 2002$, que criou instrumentos para a superação dos problemas gerados pelos resíduos sólidos de construção civil nas áreas urbanas, definindo responsabilidades e deveres, abrindo caminho para o preparo de normas técnicas, tanto para o correto manejo dos resíduos, como para seu uso pós reciclagem. Esta Resolução impõe aos geradores a obrigatoriedade da redução, reutilização e reciclagem, quando, prioritariamente, a não geração dos resíduos não puder ser alcançada.

Mas, diante das características destes geradores (de 70 a $80 \%$ dos resíduos provêm de pequenas obras), foi definida, para os municípios e Distrito Federal, a necessidade de desenvolverem e implementarem Planos Integrados de Gerenciamento, que possibilitem a expressão das responsabilidades dos geradores, diversificados em suas características.

Obedecidas às diretrizes gerais desta Resolução, aos Municípios caberá a definição da política local de gestão, assumindo a solução para o problema dos pequenos volumes, quase sempre mal dispostos, e disciplinando a ação dos agentes envolvidos com os grandes volumes de resíduos - definindo e licenciando áreas para o manejo dos resíduos em conformidade com a Resolução, cadastrando e formalizando a presença dos transportadores destes resíduos, exigindo responsabilidades dos geradores, inclusive no tocante ao desenvolvimento dos planos específicos previstos nesta Resolução 307/2002 do Conselho Nacional de Meio Ambiente (CONAMA).

Em Cuiabá, o responsável por obras de construção civil, caso não venha descartar os seus Resíduos de Construção corretamente, poderá ser multado e a obra embargada, como estabelece o Decreto Municipal $n^{\circ}$ 4.761, de 19 de Fevereiro de 2009. O Decreto estabelece medidas, diretrizes, critérios e procedimentos para a gestão dos resíduos de obras realizadas na Capital, que deverão ser encaminhados a locais impróprios ou encaminhados para os aterros sanitários. O objetivo é disciplinar a coleta, o transporte e a disposição de resíduos da construção civil, estabelecer procedimentos para eliminação, redução, reciclagem e reutilização, além de incentivar ações educativas nas questões relacionadas aos resíduos. Dentro da proposta, foi prevista a criação de centros de beneficiamento, reciclagem e disposição final dos materiais e a abertura de microcentros de recebimento e triagem de pequenos volumes.

A partir da Lei Municipal, surgiu em Cuiabá à primeira empresa para realizar a triagem, reciclagem e destinação final dos Resíduos de Construção Civil. Isso significou um grande avanço ambiental, significava por um lado, que os geradores e as transportadoras de entulhos não mais destinariam os seus resíduos em locais inadequados, algumas vezes em áreas de proteção ambiental, e por outro lado, era formalizado procedimentos administrativos para a destinação correta de tais resíduos, envolvendo a Prefeitura Municipal, os geradores de resíduos e a empresa privada ECOAMBIENTAL, administração da Área de Triagem e Disposição dos Resíduos. Esta área de destinação dos resíduos foi devidamente licenciada no órgão ambiental estadual, estando apta a recepcionar os resíduos de construção civil.

Esse estudo apresenta dados e discute a situação do gerenciamento dos resíduos de construção civil na capital do Estado de Mato Grosso, avaliando tecnicamente o modelo vigente de gestão, bem como, propondo adequações e melhorias para o setor. Segundo o Núcleo Permanente de Gestão Integrada do Plano Integrado de Gerenciamento de Resíduos da Construção Civil (PGRCD) de Cuiabá, através de Relatório de Monitoramento 02/2011, em abril de 2006 a estimativa de geração total de RCD era de 785 toneladas/dia, sendo que boa parte de tais resíduos são destinados em locais inadequados tecnicamente, gerando poluição e prejudicando a paisagem urbana.

Esta condição acaba por agravar a situação ambiental urbana, pois as transportadoras regulamentadas repassam tal preço aos clientes, enquanto outras transportadoras deixam de dispor os resíduos no aterro, aumentando os pontos de disposição ilegal.

$\mathrm{Na}$ tentativa de contribuir com a melhoria da gestão dos RCC, este estudo abordou a questão dos resíduos sólidos urbanos na capital mato-grossense, especificamente o entulho de obras, 
visando a sua reciclagem e reutilização, bem como o transporte e a sua destinação final, de acordo com critérios técnicos e de procedimentos de boas praticas no canteiro de obra.

Portanto, a elaboração, o gerenciamento de resíduos e a reutilização estrutural de resíduos passam a ter importância não apenas ambiental, mas também legal.

Considerando os dados apresentados pelo índice de triagem da ATT de Cuiabá, é possível constatar o potencial econômico da reciclagem de tais resíduos em Cuiabá, pois com apenas 5 à $6 \%$ do total de RCD gerado no município é possível obter uma renda bruta de $\mathrm{R} \$ 12.000,00$, fazendo apenas a triagem desse material, imagine então caso o município venha estruturar uma política que conceba a triagem e a reciclagem de $100 \%$ do RCD gerado, o que poderia gerar dezenas de postos de trabalho, além de oportunizar renda para retirar dezenas de famílias da linha da pobreza.

Se não bastasse a importância econômica e social da triagem e reciclagem de $\mathrm{RCD}$, conforme os dados apresentados pela ATT demonstra, não se pode esquecer também da importância ambiental, com a redução de áreas de passivo ambiental, hoje utilizadas irregularmente como depósito de tais resíduos.

Enfim, conforme análise do próprio Núcleo Permanente de Gestão do Plano Integrado de Gerenciamento dos Resíduos de Construção Civil de Cuiabá, os dados do quadro 12 demonstram o desempenho predominantemente negativo da destinação adequada de RCD, indicando a necessidade de ações efetivas de educação ambiental e fiscalização integrada da SMTU e SMADES, ações estas que possibilitariam a ampliação do atual índice de triagem na ATT de Cuiabá.

\section{CONSIDERAÇÕES FINAIS}

Este trabalho faz um levantamento investigativo e uma abordagem específica sobre as implicações da utilização do atual modelo de gerenciamento de resíduos de construção civil em Cuiabá. São demonstradas as implicações do gerenciamento inadequado dos resíduos de construção civil e suas conseqüências ambientais na área urbana. É destacada a necessidade de uma proposta sustentável resultar de uma construção coletiva baseada em princípios de sustentabilidade ambiental, viabilidade econômica e inserção social, buscando o equilíbrio no gerenciamento de tais resíduos.

Durante muitos anos, os resíduos de cons- trução civil tiveram disposição final de forma insustentável do ponto de vista ambiental, gerando centenas de pontos de descarte, representando áreas de focos de poluição visual e de contaminação e poluição, sem que houvesse maiores restrições a tal prática.

Recentemente, foi proposto pela Prefeitura municipal de Cuiabá um novo modelo de gerenciamento dos resíduos de construção civil, com o propósito de reduzir ou mesmo acabar com a prática do descarte irresponsável de tais resíduos, no entanto, muitos entraves técnicos e financeiros demonstram que ainda está longe da solução do problema. Através do diagnóstico que é aqui apresentado da situação atual são discutidas medidas e recomendações de sustentabilidade ambiental na atividade geradora de resíduos de construção civil, servindo de base para que, no futuro, a concepção de um programa de gerenciamento adequado de tais resíduos que envolva todos os segmentos envolvidos, oportunizando a ampliação do índice de triagem de RCD, bem como, a estruturação de uma cadeia de reciclagem de tais resíduos na capital mato-grossense.

\section{REFERÊNCIAS BIBLIOGRÁFICAS}

AB'SABER, Aziz, in Ciências da Terra e do Meio Ambiente: diálogos para (inter) ações no Planeta. Org de Heraldo Campos e Attico Chassot - São Leopoldo: Ed. Unisinos, 1999. 284 p.

ABRAMS, P., e E.A. WRINGLEY, Tows in Societies. Essays in Economic History and Historical Sociology. Cambridge: Cambridge University Press, 1978, $490 \mathrm{p}$.

ALMEIDA, G.A., in Administrando a água como se fosse Importante, Dowbor, L. e Tagnin R. A. São Paulo: Editora Senac, 2005, 290 p.

BISIO, A.T. e XANTHOS, M. How to manage plastics waste. Hanser, New York, 1995, 365 p.

BERTALANFFY, Ludwig von. Teoria geral dos sistemas. 2. ed. Petropolis: Vozes, 1975, 680 p.

CALDERONI, Sabetai. Aspectos Econômicos da reciclagem do lixo: Viabilidade econômica e metodologia de mensuração aplicada aos casos do município de São Paulo e do Brasil. Resid'99 Seminário Sobre resíduos sólidos. São Paulo: ABGE, p. 121-139, 1999. 
CLARK, P. A Evolução das Cidades - História em Revista. Rio de Janeiro, RJ, Abril Livros, 1991, 176 p.

EIGENHEER, E. M., Lixo, morte e ressurreição . Comunicações do Iser, Rio de Janeiro, v. 34, p. 67-68, 1989.

GRIFFITH, J. J. e BERDAGUE, C. Autopoiese Urbana e Recuperação Ambiental. Saneamento Ambiental, São Paulo, N. ${ }^{\circ}$ 120, maio/junho 2006, pág 65-70

GIL, Antônio Carlos. Técnicas de pesquisa em economia e elaboração de monografias. São Paulo, SP: Editora Atlas S.A., 2000.

GUIMARÃES, L. T. Utilização do Sistema de Informações Geográficas (SIG) par Identificação de Áreas Potenciais para Disposição de Resíduos na Bacia do Paquequer, Município de Teresópolis, RJ. Dissertação de Mestrado. Universidade Federal do Rio de Janeiro, RJ, 2000, 176 p.

HYNDS, P.D., GRACE, P. M. e DODD, V.A., A Critical Assessment of Aerobic Composting as Part of Solid Waste Manegement Solutios for Irish Institutions. The Journal of Solid Waste Technology and Manegement, University College Dublin, Ireland, $\mathrm{N}^{\circ}$ 2, 2004, disponível em http:// www2. widener.edu/ sxw0004/21CONF.html, acesso em 19 de setembro de 2006

\section{INSTITUTO BRASILEIRO DE GEOGRAFIA E} ESTATÍSTICA, Pesquisa Nacional sobre Saneamento Básico - 2000 - Banco de Dados Agregados, Rio de Janeiro, IBGE, 2002., disponível em http:// www.ibge.gov.br/sidra, acesso em 22.03.2006

JUNG, C. F. Metodologia Para Pesquisa \& Desenvolvimento Aplicada a Novas Tecnologias, Produtos e Processos. Rio de Janeiro. Axcel Books do Brasil Editora. 2004, 312 p.

MANO, E. B. PACHECO É. B. A. V. e BONELLI, C. M.C. Meio Ambiente Poluição e Reciclagem $1^{a}$ edição - São Paulo: Edgar Blücher, 2005, 192 p.

MONTEIRO, J.H.P. Manual de Gerenciamento Integrado de Resíduos Sólidos, Rio de Janeiro: IBAM, 2001, disponível em http://www.resol.com. br/cartilha4/manual.pdf, acesso 4 de março de 2006

NAIME, Roberto. Gestão de resíduos Sólidos, uma abordagem prática. Novo Hamburgo: FEEVALE, 2004, $134 \mathrm{p}$.

NAIME, Roberto; GARCIA, Ana Cristina de Almeida. Percepção ambiental e diretrizes para compreender a questão do meio ambiente. Novo Hamburgo: Feevale, 2004, 146 p.

RUTHERFURD, E. London. Tradução de Alves Calado. - Rio de Janeiro: Record, 2000, 924 p.

VERGARA, S. C. Projetos e relatórios de pesquisa em administração. 5. ed. São Paulo: Atlas, 2004, $148 \mathrm{p}$. 